AC 2009-1237: "SUSTAINABILITY" AS AN INTEGRATIVE LENS FOR ENGINEERING EDUCATION: INITIAL REFLECTIONS ON FOUR APPROACHES TAKEN AT RENSSELAER

Dean Nieusma, Rensselaer Polytechnic Institute 


\section{“Sustainability" as an Integrative Lens for Engineering Education: Initial Reflections on Four Approaches Taken at Rensselaer}

\section{Introduction}

Over the past decade, the concept of "sustainability" has gained increasing attention across society at large and within many educational institutions. As the problems associated with globalized industrial production and the energy-intensive consumer economy worsen, new models for addressing human needs continue to arise. Given the central role of engineering in creating the tools of industrial production, distribution, and even consumption, it is not surprising that increased attention to sustainability is also evident among engineering students and educators. With already overloaded curricula, and little room for inserting additional requirements, the question arises as to how sustainability might be systematically integrated into engineering education. This paper considers both what models are out there for achieving that integration, and what strategies they employ in so doing. More specifically, the paper reviews key ways sustainability is conceptualized apart from engineering education initiatives and then describes four "models" for integrating sustainability into engineering education at Rensselaer Polytechnic Institute. The first model entails a single course on the social analysis of sustainable design, taught as a social sciences course but attempting to connect to and leverage (primarily engineering) students' disciplinary expertise and interests. The second model is a newly instituted undergraduate minor in "sustainability studies" that is offered in Science and Technology Studies (STS). This minor is targeted to students across campus and, hence, is designed to complement a variety of majors, including engineering majors. The third model is a pilot collaboration among three courses, each with a different lens on sustainable design. The fourth and final model is an effort to create a major in "sustainability studies" that would be offered by interested departments across campus, including STS, economics, mechanical engineering, civil engineering, architecture, etc. Rather than creating a single interdisciplinary degree, this model responds to existing institutional constraints by allowing each department to customize its own version of the degree.

In discussing each model below, the paper will review its basic configuration, the primary students involved and their response (as available), and instructor or developer reflections on the model's successes and challenges. Since the activities reviewed in the paper are currently unfolding at the time of writing, tentative assessments and analysis will be offered where possible. The paper will conclude with the author's assessment of the possibilities of and limitations to using sustainability as an integrative lens for engineering education more generally, especially insofar as it organizes students around addressing a particular, and arguably particularly important, set of problems faced by humanity in the $21^{\text {st }}$ century.

\section{Sustainability as "Intersections"}

Sustainability as a concept has obvious intellectual and political roots in the environmental movement of the 1970s-1990s. The language of sustainability was popularized by attention to "sustainability development" by the World Commission on Environment and Development, informally referred to as the Brundtland Commission (after its chair), whose 1987 report, Our 
Common Future, famously defined sustainable development as "development that meets the needs of the present without compromising the ability of future generations to meet their own needs." Sufficiently vague to avoid disagreement over specifics and sufficiently ambitious to encompass radical visions of change, this definition has rallied proponents of change across sectors of society, including within corporate ranks. One important spin-off concept of sustainability is "triple bottom line" (or the 3 Ps) accounting, which adds social responsibility (i.e., "people") and ecological responsibility (i.e., "planet") to economic viability (i.e., "profit") as the underlying criteria by which organizational performance should be evaluated.

Despite its many contexts of application and numerous reasonable definitions, the various approaches to "sustainability" typically share two features that distinguishes the concept from common understandings of the mainstream environmental movement and its (perceived) focus on identifying and publicizing environmental problems. The first distinguishing feature is a focus on solutions to environmental problems, or at least interventions intended to ameliorate those problems. The second distinguishing feature is systematic attention to intersections, typically the intersections of social, economic, and ecological systems. Combined, these features direct critical attention to both the constraints to and the opportunities for innovation in each of the systems under consideration, which arguably cannot be accomplished effectively entirely within any of the existing disciplinary domains but must be addressed between or among them. In the terminology of sustainable design scholar Ezio Manzini, sustainability requires both a "strategy of efficiency," or doing things better, and a "strategy of sufficiency," or simply doing less, at least in terms of production and consumption of material goods. According to Manzini's approach, "ecological quality will emerge from compound strategies and compound interventions in different areas." In each of these ways, the concept of sustainability serves to reinforce efforts to promote interdisciplinary collaboration and education, surely including undergraduate engineering education.

Despite its effectiveness in directing analytic attention to the intersection of systems, and hence the importance of interdisciplinary inquiry, the terminology of sustainability is not without shortcomings. Especially insofar as it dilutes attention to real environmental problems, for example by putting a particular company's profit margin on equal footing with environmental protection within that company's local or regional context, sustainability may serve to reinforce business as usual. In a similar vein, environmental protection proponents reasonably point to the many ways sustainability has been appropriated by corporations, either in advertising their goods (often irrespective of actual environmental impact) or in "green-washing" of their corporate image (again, irrespective of the corporation's actual historical or contemporary impact on the environment). This risk will be picked up again in the discussion below.

\section{Background: A Sampling of Efforts to Leverage Sustainability in Engineering Education}

Efforts to include sustainability approaches and content in engineering education are certainly not new, and, unsurprisingly, there has been a flood of attention to various facets of sustainability in engineering education at the ASEE Annual Conference and in similar venues over the past few years. While other scholars have systematically reviewed the range of efforts that have been put forward, ${ }^{2}$ a brief review of some of the different approaches taken is relevant to contextualize the efforts taken at Rensselaer. First, many scholars seek to facilitate the 
integration of sustainability content across engineering educational contexts and disciplines, promoting sustainability as a conceptual tool that can be used to surmount enduring shortcomings in engineering education that result in highly compartmentalized, decontextualized thinkers. ${ }^{3}$ Similarly, sustainability is seen as a tool that can "foster civic responsibility and develop informed citizens who are responsible to their professions, communities, posterity and to the world." Or it is seen as a tool for increasing student interest and engagement in engineering research. ${ }^{5}$ Others take the opposite approach, investigating how undergraduate engineering students learn in order to identify opportunities for teaching sustainability content more effectively ${ }^{6}$ or assessing the degree to which existing engineering education adequately prepares students for addressing sustainability challenges of the future. ${ }^{7}$

In terms of efforts to bring sustainability content into specific engineering classrooms, we also see a diversity of approaches, including the development of specific exercises and course modules, the development of new pedagogical tools, and creating new learning opportunities such as service learning. A common strategy used by engineering educators for promoting the uptake of sustainability content into the engineering classroom is providing course modules, including especially exercises and modules for design courses, ${ }^{8-11}$ but modules also exist for courses as diverse as numerical methods, thermodynamics, fluid dynamics, traffic management, and others. ${ }^{11}$ In addition to modules designed to be transported across courses (and institutions), engineering educators have also offered specific pedagogical tools to facilitate inclusion of sustainability content into courses, including modeling tools for dealing with the complexities surrounding globalization ${ }^{12}$ and tools for integrating sustainability content and assessing its effectiveness in transforming learning practices. ${ }^{13}$ Others have provided entire engineering courses oriented toward sustainability. ${ }^{14}$

Even more ambitious efforts exist to introduce sustainability content across engineering curricula in a variety of ways. One initiative entails infiltrating sustainability content into a variety of existing courses in an undergraduate civil engineering program to ensure that coverage of such content was not subject to variations in specific instructor interests. ${ }^{15}$ Another initiative entails development of a graduate civil engineering/green construction program that combines coursework, directed research projects, and international exchanges in a format similar to designbased, service-learning experiences. ${ }^{16}$ Educators developing new curricula sometimes rely on ABET accreditation rules (especially criterion $h$ ) and professional societies' pronouncements to justify and orient innovations around sustainability. ${ }^{17}$ One specific example is the use of ASCE's "Civil Engineering Body of Knowledge," which has "embraced sustainability as an independent technical outcome," to guide integration of sustainability criteria into a civil engineering program. ${ }^{18}$ Finally, others have reached beyond "engineering" to develop graduate programs in "Sustainability" more broadly, but which extend out of engineering perspectives and are targeted to include, but not be limited to, graduates of engineering programs. One such effort extends the project-based engineering curriculum approach to an interdisciplinary, professional "Masters of Sustainable Practice" degree program. ${ }^{19}$

\section{Four Approaches to Sustainability Education for Engineering Students}

This section reviews four different approaches to teaching sustainability at Rensselaer, with a special emphasis placed on how the approaches fit within undergraduate engineering curricula. 
The initiatives span the range of initiatives at other institutions as reviewed above. The discussion of each model will include a review of its basic institutional configuration and intentions, the primary students involved and their assessment as available, and finally instructor/curriculum developer reflections on the successes and challenges as available (all of which, of course, are interpreted by the paper's author situated as he is in an STS department). The discussion will also describe the stage of development of each approach, which necessarily impacts the amount of information available for critical assessment. Since the larger-scale initiatives are in an earlier stage of development, more detail will be provided for the lessambitious initiatives. The four initiatives to be discussed include: 1) a single course in sustainability in STS, 2) a newly offered minor in sustainability studies in STS, 3) a crossdisciplinary, multi-course collaboration around sustainable design, and 4) a proposed crossdisciplinary minor in sustainability studies to be offered by departments across the university. The following table summarizes these initiatives.

Table: Four Models for Integrating Sustainability into Engineering Education

\begin{tabular}{|l|l|l|}
\hline Type & Summary & Status \\
\hline $\begin{array}{l}\text { Stand-alone } \\
\text { course in STS }\end{array}$ & $\begin{array}{l}\text { STS course that uses sustainable design to reach toward students' } \\
\text { technical majors }\end{array}$ & $\begin{array}{l}\text { First offered Fall 2008; to } \\
\text { be offered in future } \\
\text { semesters. }\end{array}$ \\
\hline Minor in STS & $\begin{array}{l}\text { STS minor that systematizes H\&SS electives around sustainability } \\
\text { and can be easily elected by engineering majors }\end{array}$ & $\begin{array}{l}\text { Approved in December } \\
2008 \text { for the Fall term } \\
2009 .\end{array}$ \\
\hline $\begin{array}{l}\text { Cross-course } \\
\text { collaboration }\end{array}$ & $\begin{array}{l}\text { Collaborative assignments and meetings between engineering and } \\
\text { STS courses focusing on sustainable design. }\end{array}$ & $\begin{array}{l}\text { Three courses offered } \\
\text { Spring term 2009; to be } \\
\text { completed in May. }\end{array}$ \\
\hline $\begin{array}{l}\text { Cross- } \\
\text { disciplinary } \\
\text { major }\end{array}$ & $\begin{array}{l}\text { New inter-School major to be offered by traditional academic } \\
\text { departments; to use sustainability as the overarching concept in } \\
\text { determining appropriate breadth and depth requirements in each } \\
\text { field of study. }\end{array}$ & $\begin{array}{l}\text { In early planning stages } \\
\text { as of Spring term } 2009 .\end{array}$ \\
\hline
\end{tabular}

Sustainability as a Stand-alone Course in STS

Configuration: The course Sustainable Design Politics and Culture was offered by the author in the Fall term of 2008 as an upper-level H\&SS/STS elective. Being the first time offered, the course was designated as a "topics course" and was intended as a pilot for integrating sustainability content with undergraduate students' technical majors, where "technical" was understood to include all fields of engineering, architecture, and interdisciplinary design. Use of the term "design" in the course title was intended as a signal to students that, although an STS course, the domain of inquiry would revolve primarily around sustainability interventionsincluding technological innovations - and not only analysis of current environmental problems. Sustainable design interventions were divided into three categories for analysis: lifestyle decisions and individual behavioral change (e.g., consumption, energy use, transportation decisions); technological innovation (e.g., housing/buildings, energy sources and systems, transportation systems, communications systems, waste management); and institutional innovation (e.g., new business ventures, social entrepreneurship, economic policy, and new social and cultural values). Sustainable design in the domain of technological innovation was intended as an explicit and direct bridge to students' disciplinary majors (e.g., in engineering, 
architecture, and product design) and their corresponding approaches to problem solving (e.g., engineering design, architecture design, and product design). But this area of innovation was also connected to the larger forces that shape it, including bottom-up direction from consumers and top-down direction from policy makers and cultural forces.

The course was designed and portrayed as an advanced undergraduate introduction to the graduate research seminar, which included common reading and writing assignments, but also required students to carry out a significant "independent case-study research [project], where they will identify and select a high-profile sustainable design project, carefully analyze their selected project, present their insights to the entire class, and finally write up a report that describes their work and the lessons learned" (course syllabus). Importantly for the purposes of this paper, in addition to common readings, students were encouraged to identify and select a mixture of disciplinary (in their major) and interdisciplinary readings each week. They were also expected to include in their analyses attention to both technical and social aspects of their selected case studies. The goal, in both cases, was to create within each student's project an integrated understanding of "sustainability" that included analysis of both social and technical dimensions of the design approaches common in their disciplinary majors.

While students were encouraged to include technical analysis in their readings and project research, the majority of class-wide discussion revolved around more traditional STS themes, including critical assessment of how "sustainability" was envisioned within specific approaches or projects; identification of technological, economic, political, and cultural trade-offs associated with any particular approach to sustainability; identification of those most likely to benefit by or be harmed by particular solutions looking across their life cycles; etc. Here, again, use of the language of "design" helped bridge typical approaches to social analysis with the design decision-making process typical in technical disciplines. Additionally, an introduction to many of the basic assumptions and tools of sustainability studies was provided at the beginning of the term, including content similar to that reviewed in the "What is Sustainability?" section above as well as common tools like life-cycle assessment, ecological footprints, carrying capacity, etc.

Within the course's overarching structure, the students were encouraged to work independently in selecting readings, identifying and communicating what was important in them through regular written response papers, and identifying and carrying out research for their case studies. While teaching an undergraduate course much like a graduate seminar was recognized as a risk by the instructor, the potential (and hoped for) payoff was having students revert to their disciplinary training when making judgments about project selection and research trajectories. This risk and intended payoff was discussed in class, especially in the first few weeks of the semester, during which time the instructor set the tone of the course around student-led inquiry.

Students and Student Feedback: A total of 16 students enrolled in Sustainable Design Politics and Culture, 10 of whom were engineering and information technology students, 5 architecture and design students, and 1 science student. All students were seniors with the exception of 2 sophomores, both of whom were engineering majors. Exactly half of the students were women and half were men. Only one student was visibly from an under-represented minority group. (Between 20 and 30 additional students expressed interest in the course and/or initially enrolled but then dropped the course during the open enrollment period in the first two weeks of the 
semester, reasons for which will be speculated on below. Also, one enrolled student stopped attending class early in the term.) A slight majority of the enrolled students came to the class with a clear commitment to environmentalism already established, whereas the rest were sympathetic to the idea of sustainability and interested in learning more.

Overall student evaluations for the course were positive. Using the IDEA Center's student ratings of instruction evaluation forms with a 5-point Likert scale, students' overall rating for "Excellent Course" was 4.7 (raw score). ${ }^{20}$ In anonymous written feedback provided via final course evaluations, students were relatively consistent in their assessment of the course. In responding to a query regarding the course's strengths and weaknesses, students generally expressed that the course was well structured and well executed, except insofar as specific assignments were concerned. Many students suggested "better guidelines for homework submissions and [research] papers" or something similar, including criticism that the instructor was not clear in "what he was looking for" in assignments.

For those students who expressed concern over the assignments, the risk in structuring the course similar to a graduate course did not seem to pay off. Regardless of the skills that might have been gained, when looking back upon the course-and perhaps especially in relation to what they had come to expect courses to be like-most students seemed to be unsatisfied with the student-led inquiry model, or at least with its implementation in this course. As one student put it, "Not having a strong background, if any at all, in this area, I floundered a lot in the beginning, trying to gain a firm grasp of the course topic." Another student, however, took the opposite position, even alluding to the trade-off between instructor guidance and student-led inquiry in his comment: "Perceived weaknesses in regard to [the instructor] providing direction became a strength by letting students guide themselves." Related to student dissatisfaction regarding the extend of guidance/structure provided by the instructor, many students suggested the instructor require more common readings next time- too much independent work made it more difficult for students (and the instructor) to find common themes in classroom discussions. Additional comments included a range of suggestions about, criticism of, or comment upon specific details of the course, instructor, and topic. Despite a good dose of focused criticism, student feedback showed they were very pleased with the course overall. One student even claimed: "Best HASS class I have taken."

Instructor's Reflections: Student feedback, surely, must be taken with a grain of salt, whether positive or negative. Part of the challenge in education-and particularly education in the humanities and social sciences for engineering students - is to distinguish what students want to learn from what they need or at least ought to learn. Although students at Rensselaer are characterized as being extremely hard working, they are not widely known for "a love of learning." This matter is particularly relevant to the tension, as established above, between instructor and student-led inquiry. To what extent, one may ask, is it sensible to expect an undergraduate non-major to invest considerable intellectual effort in an independent research project for an elective H\&SS course? The risk identified at the beginning of the term in structuring an undergraduate elective course like a graduate research seminar proved to be real, even though the consequences were modest. Clearly, the students were uncomfortable with their sense of "floundering," but that discomfort may be essential for the educational process, especially in domains with as much uncertainty as sustainability studies, where multiple complex 
systems — social, technical, and ecological—intersect and interact. This is not to dismiss student feedback, especially constructive criticism, but instead to place it in context of the larger educational (and cultural) environment. (That said, much of the students' criticism of the course was exactly on target—especially regarding reading selections.)

The open-endedness of the course's requirements was of mixed success, but the open approach to the topic of sustainability was a clear success. All students appeared to be satisfied with the way the course was framed and the specific content that was covered (with the exception of specific readings, as mentioned above), and most students did end up identifying and carrying out case study research projects connected to their disciplinary majors. Hence, it appears the course met one of its key objectives, namely using the concept of sustainability as a tool to connect social analytic approaches to topics arising from students' primary disciplines, including especially those in engineering and architecture. (It should be noted here that although similar challenges exist in bringing social analysis to architecture and design students as with engineering students, traditional education in those disciplines is already oriented more toward social analysis and, hence, the task is easier there than with engineering.) That the course was also centered on sustainable design, and not just sustainability generally, also helped bridge social and technical analysis, as mentioned above.

Despite the course's effectiveness in bringing STS and social analysis to students' disciplinary majors (as determined by the students' project selections), the course was not especially effective in integrating social and technical analysis into the same project. The instructor's regular encouragement of students to integrate technical analysis into their research and reporting did not bear fruit with two significant exceptions. One engineering student and one architecture student included research-based technical analysis in their case study reports, each of which had nicely integrated content. The majority of students, however, did not follow the instructor's suggestion to integrate technical information and assessment into their reports and instead merely described the basic technical foundations underlying the selected topics of study. It never became apparent why students did not accept the invitation to connect the case study assignment more directly to their majors, but three possible explanations come to mind. First, they may have needed more targeted direction to actually execute the integration-direction that would have been difficult to provide (without considerable one-on-one advising) given the diversity of majors represented in the course. Second, given their aptitude for determining what instructors "are looking for," students may have decided that, as an STS faculty member, the instructor was not really interested in the technical details of their projects despite his invitation to include it. Third, the students may not have been interested themselves in including the technical content, at least not in this course. As is common among engineering students taking H\&SS elective courses, they may well have wanted "a break" from the technical core of their curricula.

Sustainability as a Minor in STS

Configuration: In December 2008 a new minor in Sustainability Studies was approved to be offered by the STS Department at Rensselaer starting in the Fall semester of 2009. Despite some initial concerns regarding the name of the minor (after all, no single discipline "owns" sustainability), the minor proposal succeeded in winning Institute approval. The new minor was motivated by several converging factors, including the recent hiring of STS faculty with research 
agenda that included sustainability and the desire by sponsoring faculty 1) to promote environmental awareness among students, 2) to bring STS analytic tools to more undergraduate students (there are relatively few students majoring in STS at Rensselaer), and 3) to facilitate systematic interdisciplinary education for any Rensselaer student.

The sustainability studies minor has a very simple structure, as is typical of minors offered at Rensselaer. Students are required to take one 1000-level course, one 2000-level course, and two 4000-level courses from a menu of options. Courses at each level are designed to achieve different goals and carry different content requirements. Without getting into detail, the 1000level courses are designed as introductory "hooks" to elicit interest in the topic of sustainability generally and the minor specifically. These courses work within our university's First-Year Studies program, which ensures incoming students have access to relatively small, discussionbased courses during their first year. The 2000-level course, Environment and Society (only one is approved currently, but others will be developed), covers key concepts in sustainability studies that will be elaborated or built upon in 4000-level courses. The 4000-level courses, on the other hand, are designed as fulfilling a "depth requirement" around a range of specific topics relevant to social studies of sustainability, including global environmental problems, environmental health, international food/agricultural politics, sustainable design (as discussed above), and others.

While much remains to be learned in terms of implementation and administration of the minor, as well as how it will be responded to by students, it is possible to comment presently on the underpinnings of the minor's design as well as its potential to facilitate interdisciplinary inquiry among students. Foremost among the minor's conceptual underpinnings is the importance of bringing "big picture" considerations to the education of Rensselaer students, and here "big picture" refers specifically to understanding broad social/cultural assumptions, biases, and goals that lie in the background of typical inquiry and problem solving but that shape much of human behavior. This is especially true for engineering and science students, whose curricula do not systematically introduce such content except as achieved haphazardly through H\&SS electives and, for the engineers, professional development courses. In most H\&SS elective coursesindeed in the very model of H\&SS electives as designed to "round out" engineering students' education-systematic consideration of big-picture issues is not the goal. Rather, such courses serve to introduce students to one more among many academic disciplines and the key problems faced and tools employed by those disciplines. This model may have its merits in certain cases, but too many engineering students experience H\&SS electives as disconnected from their disciplinary education. Like the course discussed above, the sustainability studies minor is intended to help overcome this deficiency.

Another conceptual underpinning of the minor is the importance of understanding the complexity of modern social problems and how (equally complex) modern social-technological systems contribute to both causing and solving various facets of those problems. Complex, global environmental problems, like climate change or the dispersion of toxic chemicals throughout the environment, highlight the improbability of simple technological fixes "saving the day" as it were. Instead, like the field of STS does generally, the sustainability studies minor assumes, and is designed to teach, that solutions to contemporary problems are most likely to be found through Manzini's "compound strategies" built upon interdisciplinary collaboration. The conceptual 
grounding in interdisciplinarity not only makes sense theoretically; it also facilitates orienting the minor toward a variety of undergraduate major disciplines. Thus, in developing the minor, faculty participants agreed on the importance of connecting sustainability education with students' disciplinary interests and career aspirations. And luckily, despite pedagogical shortcomings with the electives approach to big-picture education for most engineering students, the curricular format makes it easy for engineering undergraduates to elect the sustainability studies minor in STS within their existing curricular templates. H\&SS electives are simply replaced with specific courses that meet the sustainability studies minor requirements.

Students and Student Feedback: Because the sustainability studies minor will not be available for students to officially elect until Fall term 2009, nothing can yet be said about student experience with the minor. What can be said at this point is that within six weeks of officially announcing the approval of the minor, several dozen students have expressed interest in it through a variety of channels - individual faculty members, student advisors, and departmental administrators. One senior engineering student who is to graduate after completion of Fall term 2009 has even rearranged her entire final semester so as to be able to earn the minor (with prior course work satisfying the 1000 and 2000-level requirements). Not surprisingly, the student clubs whose interests revolves around different facets of sustainability also expressed considerable interest in the minor, with some clubs doing the initial work to solicit interest and then get the word out.

Program Developers' Reflections: As with student experiences, at this early stage there is little to reflect on in terms of the minor's primary strengths and weaknesses. As indicated above, the naming of the minor created some debate, particularly given the fact that other departments were similarly interested in matters of sustainability. Several facets of the naming problem surfaced, including disciplinary territory setting and protection and the question of whether any discipline/department should be allowed to offer a minor in what is inherently an interdisciplinary pursuit. Among the program developers, there was considerable discussion of the currency of "sustainability" as the defining word and concept and comparison of its relative merits to alternatives like "environmental studies." Ultimately, program developers agreed that "sustainability studies" was desirable for a variety of reasons. It connected well to perceived student interest and the language used by students to express their interest in environmental issues. The focus on sustainability could be justified within STS given the field's interdisciplinary approach and the fact that, as a scholarly field of inquiry, STS concerns itself with the very creation and maintenance of disciplinary boundaries, including those in science and engineering. Finally, from a pragmatic perspective, other options for naming the minor were not sufficiently interesting, apt, or sensible: "social scientific studies of sustainability" was too much of a mouthful, "environmental studies" suggested a grounding in environmental (natural) sciences, and anything with "STS" in the title was simply too confusing. Certainly, the problem of corporate appropriation of the language of sustainability, and its resulting association with "greenwashing" of business-as-usual activities, raised concern among the program developers, but they decided, ultimately, to respond to student interest and, insofar as possible, contribute to sustainability's re-appropriation as a critical, productive contribution to thinking about innovations in the future. 
Sustainability as an Interdisciplinary Cross-course Collaboration

Configuration: The third initiative for integrating sustainability into engineering education at Rensselaer entails aligning the content, schedule, and assignments of three different courses and having students collaborate on projects that span the courses. This initiative is in-process during the current (Spring 2009) semester. One course, "Sustainability and Design," is a 4000-level technical elective offered by the Mechanical, Aerospace, and Nuclear Engineering Department and targeted primarily to engineering students. A second course, on product design and development, is a 4000-level core engineering course and is required of and restricted to students in the Program in Design and Innovation (PDI), which has a strong focal area in sustainability. The third course, "Social Entrepreneurship and Sustainable Communities," is a 4000-level H\&SS elective offered by the STS Department and open to students across the university. Rather than being motivated primarily by a desire to bring sustainability to engineering education in this way, the cross-course collaboration was conceived of by faculty with shared interest in sustainability, design, and entrepreneurship. The proximate impetus for connecting the courses was a request for proposals in entrepreneurship curriculum development, which sought creative new models for integrating entrepreneurship content across programs. The faculty involved saw this as an opportunity to connect entrepreneurship and sustainability in the context of design and to advance education in the two areas together. Clearly, this initiative is unique and may not be exactly replicable in other settings; however, it nevertheless provides a collaborative model for the teaching of sustainability and contributes to understanding the potential of the concept of sustainability for bringing together diverse course content across diverse disciplines in a coherent way. And again we see the use of "design" as the place in the engineering curricula where the connections to sustainability and interdisciplinary collaboration are made.

As with the sustainability studies minor discussed above, the administrative details of this initiative will not be reviewed here, but the conceptual underpinning of the cross-course collaboration as a strategy for teaching sustainability is worthy of elaboration. Most directly, the pedagogical goal of the initiative is to provide an opportunity for different types of students, mostly engineering majors, to draw connections across courses and, more importantly, across disciplines. In this case, the common theme of sustainability is used to connect content on engineering design and manufacturing, product design and development with a focus on market analysis and marketing, and social entrepreneurship (i.e., advancing social goals through the creation of non-profit or hybrid profit/non-profit organizations). The ultimate deliverables of this collaboration include a detailed product design, fully specified and with its manufacturing plan, marketing plan, and new business venture-for-profit, non-profit, or hybrid — to disseminate the new product. As with the "Sustainable Design Politics and Culture" course described above, we see here the intersection of technical, social, and institutional approaches, but in this case, instead of just studying design, the students are actively engaging in the design process-including engineering design and product/industrial design as well as other design activities surrounding new enterprise development. Through five collaborative meetings distributed over the term, student teams from each of the three classes meet to share progress, provide each other feedback, and then hand-off major project components. While each course has its own independent assignments and requirements, the primary assignments connect across the courses and will entail contributions from students across all three courses. 
Students and Student Feedback: Because this collaboration is in its initial phases, little can be said of student experiences or feedback. The first joint meeting of students entailed Sustainability and Design (engineering course) students presenting their initial product concepts to students in the PDI (product design) course. As the concepts were still in early stages of development, most questions entailed clarification of basic functionality (how it works), design team goals (what is to be achieved), or status (what is decided/remains to be decided). While the process was effective in handing over initial concepts, the window for the joint meeting was short-90 minutes for nine concepts/team presentations-so there was little opportunity to voice concerns over or reflections on the process and progress to that point.

Instructors' Reflections: The comfortable fit between sustainable design and entrepreneurship, and in particular social entrepreneurship, is central to the initial workability of this particular collaboration. For the most part, students have self-selected into the "Sustainability and Design" course and the "Social Entrepreneurship and Sustainable Communities" course because of their interest in sustainability. Similarly, most students in the PDI course are also already interested and committed to sustainability. Given the students' common interest in sustainability, it is not difficult to integrate entrepreneurship content - especially in the open way in which entrepreneurship is defined across the courses, as a way of aligning people and resources to achieve one's goals or vision. Even with the easy conceptual alignment of entrepreneurship and sustainability in the context of new product concept design and even with a good working relationship among the primary faculty members involved, the administrative challenges of aligning assignments and schedules across three different classes has proved to be burdensome. The initial goal was for students across the courses to meet on a weekly or semiweekly basis, but that was deemed to be overly ambitious early in the course planning process. In its place, a process with clearly specified product design phases, with clearly delineated assignment of responsibility among the classes, was devised. This process was mapped onto five joint meetings spread across the semester, with only two of those meetings involving students from all three courses (the other three meetings entailed students from two of the courses attending). This was seen as a reasonable compromise between intimate collaboration and the reality of administrative and scheduling constraints.

\section{Sustainability as a Cross-disciplinary Major}

Configuration: Of the four sustainability initiatives discussed in this paper, this one is in the earliest phase of development, but sufficient curricular potential exists to deserve including an introductory summary of the idea and some brief reflections. The basic idea is to create a "sustainability studies" degree program with concentrations operating much like majors. Interested departments would develop their own version of the degree, so there would be offerings in, for example, sustainability studies in mechanical engineering, sustainability studies in earth sciences, and sustainability studies in STS. As departments began offering new course options covering various facets of sustainability, those courses would be made available to students in other concentration areas as options for satisfying distribution requirements. As it stands now, the sustainability studies minor in STS is already in place to be used as the H\&SS distribution requirement for any new sustainability studies degree option that was to be offered by any of the engineering or science departments. The details are yet to be hashed out, and the 
plan may well turn out to be unworkable as envisioned. In that case, the default option of a new sustainability studies major offered by any one department becomes more desirable and may well be pursued. Regardless of the path taken, new degree offerings require New York State approval, so the typical institutional challenges of associated with doing something significantly divergent from the status quo will be present here as well, and because of this approval process, the formal manifestation of any version of the new major is probably two or more years away.

Program Developers' Reflections: These reflections are based on several brainstorming meetings among core program proponents and one open meeting to present the idea to and get feedback from interested faculty members in several academic departments from across campus. It is interesting to note that the original idea of a university-wide degree option for sustainability studies was rooted not in faculty commitment to interdisciplinary inquiry in sustainabilitythough that commitment is readily apparent—but instead in a more mundane politics of compromise. In fact, the approach was first floated in response to external push-back on the idea that the STS Department sought to offer a sustainability studies minor. Given that push-back, STS faculty interested in pursuing offering the major in sustainability studies decided it would be prudent to take a more inclusive stance. The current model is based on a similar approach taken with our Information Technology (IT) program, which offers inter-School Bachelors and Masters degrees. Rensselaer's IT program, like the various models for teaching sustainability reviewed here, systematically integrates social analysis with the technical core to create a cohesive interdisciplinary educational experience. Similarly, current thinking about the sustainability studies major starts with the need for interdisciplinary breadth. The question that remains to be resolved, however, is how best to go about the disciplinary depth in a way that accommodates the desired interdisciplinary breath. In terms of the conceptual underpinnings of interdisciplinary coverage in each department's sustainability studies curriculum, a lot will depend on how the distribution requirements are managed in each version of the major offering. And the threat of going too far with the integration is there as well; certainly none of the sustainability studies major developers wants or expects all of a student's coursework to center on sustainability.

\section{Sustainability as Integrative Lens for Engineering Education}

As we see across the variety of models for integrating sustainability into engineering education reviewed above, the concept has considerable potential for stimulating both engineering student interest in making cross-disciplinary connections in their education and faculty experimentation and innovation in cross-disciplinary and interdisciplinary pedagogy. As indicated above, these efforts are just a sampling of what is being done around sustainability in engineering education at Rensselaer, not to mention initiatives nationally and internationally, and these efforts connect to a range of other approaches to pedagogical and curricular innovation, including project/problembased learning, design-centered curricula, STS courses offered within engineering schools, and other approaches.

In the context of multiple approaches to sustainability, attention should be directed to what the models described above offer conceptually as well as the challenges and shortcomings of using "sustainability" as the integrating concept. In terms of what the above models offer, the most important strength probably lies in the posture each initiative takes with regard to interdisciplinary inquiry. Rather than looking at sustainability content as something independent 
of technical engineering classes or as something that can be "added on" without impacting either the sustainability content itself or the core content of the various engineering disciplines, the models above strive to integrate, insofar as possible, sustainability coursework within existing disciplinary approaches. This integration is important not just so that engineering students can better relate to it and imagine it contributing to their future careers as engineers, but also because it more accurately responds to how knowledge is marshaled in solving most real-world problems, namely by pulling together what is readily accessible to the people at hand-people who are typically operating within strict time and resource constraints. The importance of this effort is also underscored by the recognition that innovation increasingly happens at the intersections of disciplines, fields, and social networks. Integrating sustainability content within engineering curricula not only exposes engineering students to the main challenges and tools of interdisciplinary sustainability inquiry, but it also prepares them to operate at the margins of their technical disciplines - at least as they are currently configured. (This is also true of most environmental engineering programs, whose approach is similar to other engineering disciplines: focused on a technical core with "rounding" courses offered in the same buffet-style format, with electives unconnected to the major's technical core.)

The integration of sustainability content into various engineering curricula is facilitated by faculty within engineering departments reaching out toward those teaching sustainability from other perspectives, especially natural sciences and H\&SS/STS. But where the majority of disciplinary expertise in "sustainability" — as an overarching approach to understanding global problems and their solutions-exists outside of engineering departments, the integration requires those faculty members to be willing to reach in toward engineering curricula to ensure the bridge is built. The emphasis in the examples above is mostly of the latter sort, where STS faculty are attempting to reach in toward the engineering curricular content and to connect sustainability content there-with the critical support of a handful of engineering faculty. This is due in part to the author's situation within an STS department and in part to the fact that engineering disciplines dominate our university in terms of number of faculty, number of student majors, research funding, and reputation, so H\&SS departments have strong incentives to accommodate engineering students' skills, perspectives, and outlooks. Surely, a more radical integration of sustainability content could be achieved by a critical mass of change agents working within engineering departments and schools, or better within ABET, but the existing curricular format is well entrenched and will almost certainly resist radical change in short time. ${ }^{21}$ Despite having a critical mass of faculty interested in sustainability as an overarching conceptual lens for interdisciplinary undergraduate education, insofar as it connects to engineering education, all the experimentation above is operating within the flexibility afforded by the technical and H\&SS options already existing in engineering curricula. We are still far from having the necessary influence to alter core requirements of any of the engineering programs, either from the inside or the outside.

It should be qualified, however, that the point of this analysis is not to argue whether sustainability should serve as an overarching concept for engineering programs. That is a larger conversation which would require consideration of many more perspectives and constraints. Instead, the point here is to explore what integrative pedagogy looks like and, in particular, to assess the potential role to be played by "sustainability" in enabling and/or promoting that integration. What the models above show is that sustainability can, in fact, be used as a 
conceptual linchpin to connect engineering and H\&SS (or liberal arts) approaches to understanding, and perhaps attempting to solve, complex, social-technological environmental problems. It also shows that the terminology of sustainability is attractive to at least some engineering students and serves to motivate their interest in interdisciplinary inquiry. Given the early stages of our experiments, what remains to be determined from this analysis is whether sustainability can serve as an effective integrative lens within engineering education from the perspective of a majority of engineering faculty and students. On-going collaboration between scholars interested in sustainability - from engineering and other relevant disciplines-will provide cumulative experience that will begin to answer that question.

\section{Acknowledgements}

The author would like to thank his collaborators in the pedagogical experiments described above_-especially David Hess, Michael Jensen, Daniel Walczyk, Kim Fortun, Abby Kinchy, Michael Mascarenhas, and Atsushi Akera - as well as the LED program chair and two anonymous reviewers for their careful reading of and insightful suggestions regarding the paper.

\section{References}

${ }^{1}$ Vezzoli, C., and Manzini, E., Design for Environmental Sustainability, London: Springer, 2008. P. 13.

${ }^{2}$ Sharma, M. P., and Peters, R. W., "A Study of Integration of Sustainability in Engineering Curricula at U.S. Colleges and Universities," in Proceedings of the 2008 American Society for Engineering Education Annual Conference \& Exposition.

${ }^{3}$ Bosscher, P. J., Russell, J. S., and Stouffer, W. B., "The Sustainable Classroom: Teaching Sustainability to Tomorrow's Engineers," in Proceedings of the 2005 American Society for Engineering Education Annual Conference \& Exposition.

${ }^{4}$ Orndoff, C., "A Student Overview in Practical Sustainability," in Proceedings of the 2008 American Society for Engineering Education Annual Conference \& Exposition.

${ }^{5}$ Grimberg, S. J., Langen, T. A., Compeau, L. D., and Powers, S. E., “A Theme-Based Seminar on Environmental Sustainability Improves Participant Satisfaction in an Undergraduate Summer Research Program," Proceedings of the 2008 American Society for Engineering Education Annual Conference \& Exposition.

${ }^{6}$ Theis, R., Watkins, P., and Beck, M. A., "Pathways to Learning: Orchestrating the Role of Sustainability," in Engineering Education," in Proceedings of the 2008 American Society for Engineering Education Annual Conference \& Exposition.

${ }^{7}$ Vanderburg, W. H., "On the Measurement and Integration of Sustainability in Engineering Education," in Journal of Engineering Education, 1999 (April), pp. 231-235.

${ }^{8}$ Gaughran, W., Burke, S., and Quinn, S., "Environmental Sustainability in Undergraduate Engineering Education," in Proceedings of the 2007 American Society for Engineering Education Annual Conference \& Exposition.

${ }^{9}$ Nair, I., "Life Cycle Analysis and Green Design: A Context for Teaching Design, Environment, and Ethics," in Journal of Engineering Education, 1998 (October), pp. 489-495.

${ }^{10}$ Hollar, K. A., and Sukumaran, B., "Teaching Students Sustainability: An Interdisciplinary Design Project for Sophomore Engineering Students," in Proceedings of the 2002 American Society for Engineering Education Zone 1 Conference.

${ }^{11}$ Catalano, G., Baillie, C., Riley, D., and Nieusma, D. "Engineering, Peace, Justice, and the Earth: Developing Course Modules," in Proceedings of the 2008 American Society for Engineering Education Annual Conference \& Exposition. 
${ }^{12}$ Sreenath, S. N., Mesarovic, M. D., and Vali, A. M., "Education on Globalization and Sustainability for Engineers," in Proceedings of the 2003 American Society for Engineering Education Annual Conference \& Exposition.

${ }^{13}$ Zhang, Q., Zimmerman, J., Mihelcic, J., and Vanasupa, L., "Civil and Environmental Engineering Education (CEEE) Transformational Change: Tools and Strategies for Sustainability Integration and Assessment in Engineering Education," in Proceedings of the 2008 American Society for Engineering Education Annual Conference \& Exposition.

${ }^{14}$ Chen, K., Vanasupa, L, London, B., Savage, R., "Infusing the Materials Engineering Curriculum with Sustainability Principles" in Proceedings of the 2006 American Society for Engineering Education Annual Conference \& Exposition.

${ }^{15}$ Robinson, M., and Sutterer, K., "Integrating Sustainability into Civil Engineering Curricula," in Proceedings of the 2003 American Society for Engineering Education Annual Conference \& Exposition.

${ }^{16}$ Beckman, E., Besterfield-Sacre, M., Kovalcik, G., Needy, K., Ries, R., Schaefer, L, and Shuman, L., "Combining Graduate Studies, Research, and International Experiences in Sustainability," in Proceedings of the 2006 American Society for Engineering Education Annual Conference \& Exposition.

${ }^{17}$ ABET's criterion $\mathrm{h}$ for engineering program explicitly refers to the environmental context: "the broad education necessary to understand the impact of engineering solutions in a global, economic, environmental, and societal context."

${ }^{18}$ Lynch, D., Kelly, W., Jha, M., and Harichandran, R., "Implementing Sustainability in the Engineering Curriculum: Realizing the ASCE Body of Knowledge," in Proceedings of the 2007 American Society for Engineering Education Annual Conference \& Exposition.

${ }^{19}$ Hadgraft, R., and Goricanec, J., "Engineering Sustainability?!" in Proceedings of the 2007 American Society for Engineering Education Annual Conference \& Exposition.

${ }^{20}$ IDEA also provides adjusted scores, which are intended to account for "extraneous factors" not controllable by the instructor. The adjusted score for the course was 4.1. For more detailed information on the IDEA student ratings system, see http://www.theideacenter.org/.

${ }^{21}$ Again, ABET's criterion $\mathrm{h}$ requires attention to the environment as well as other facets of "broad education," and many engineering curriculum reformers use criterion h effectively in support of their efforts. However, criterion $\mathrm{h}$ is both extremely broad and sufficiently vague to allow even modest educational efforts to satisfy it. Furthermore, the environmental context competes for attention among other expansive domains, including the global context, the economic context, and the societal context. 